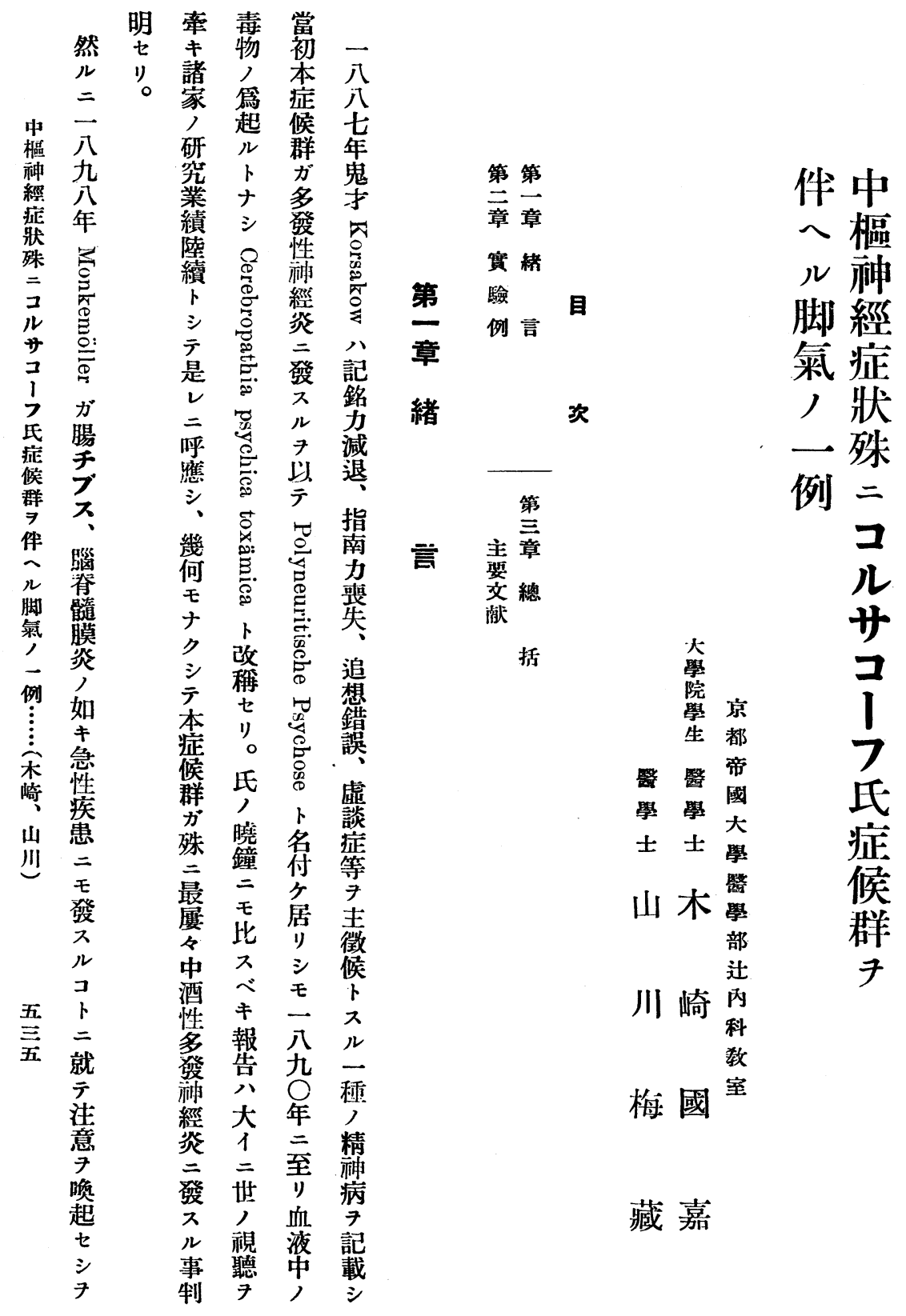


事 朁 記 家 患

り集キ族者

: 歷气 患中

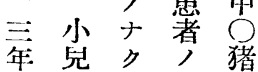

前期 殊 妻 (

リ 健 精 輕 郎

每康 神度五

年病吉士

氣 $シ$ 溃 脑歲

霍 亗傳 炎男

居歲

》分 患 亟

。䏚

型莫莫采

少 劣

少䍜准

量 シ 然

シ腹 誘 現 モ

病痛男病全

卶訴》飲

二 輕患酒

輕夕度者七

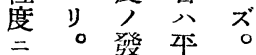

存其筫素氣

七後学便筫

シ 流り就 八

麻動 テ 勝 小

瘦食下千膽

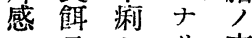

次 $\underset{7}{ }$ 攝 $シ$ 方

第》水

具 樣 昭

增 量 黄 和

强色十

七著便劣

○排 八

十制泄月

月 限 济

日居少 何

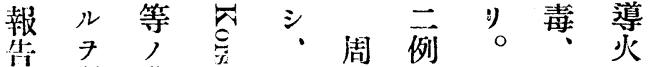

七得業范 コ知, 然三卜

ンザ續导レノ磨りリナ

トル 7 二如痻卜丿三

スモ見症關 ク性雖精本榀 儿 候 ス 脚脚脚神症神 尠二群儿氣氣氣病候縃

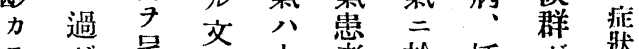
ラギ呈献本著於妊唯狀

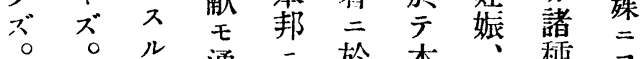

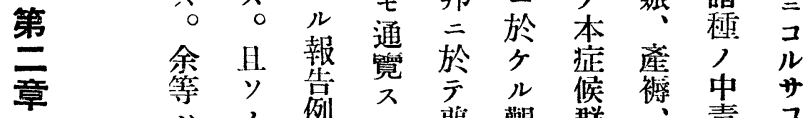
八ノ例 ル

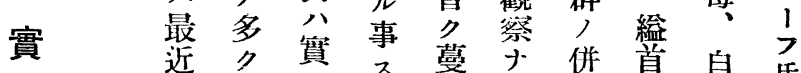

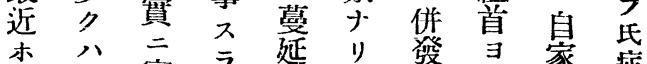

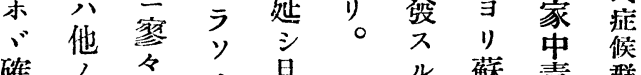

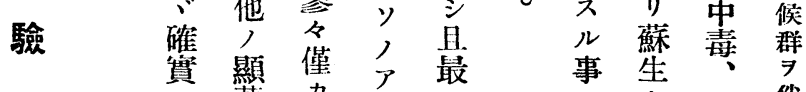

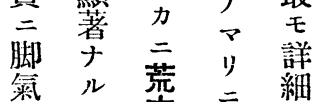

例

二合末多

本㑞今多研

症症今村ナ數究

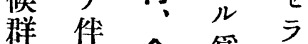

比金篇

侀明井二至

發力和至、

七二和難勇

リ脚田当ル

氣、牀壬

推当佃況端

定り、在倪

來金在

得レ美ルぶ

ルル、二カ

例モ小力

二, 沼、ザ

遭卜州

遇推多ラ干

タ定 思 ズ、態

ルル 維、精 容

7 八中椳,

以. 踣 島 症 症

テ躇狀 狀

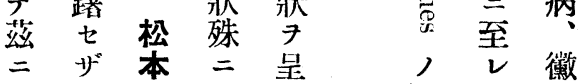

極学中 件

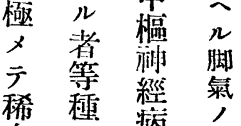

稀種病 釆

二八 例

シ 笶 急

テ 患 性

У

, 於 ビ 崎

報告恲性山

告併傳 川 


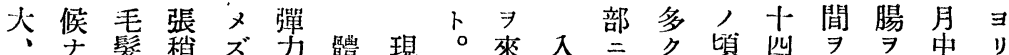

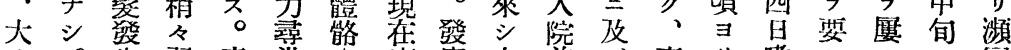
サ。生弱意常大症病十前ビ高り哓 シ ま 回 尋顏 牀

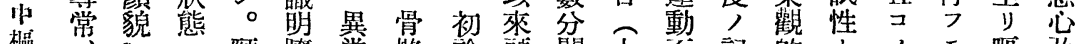

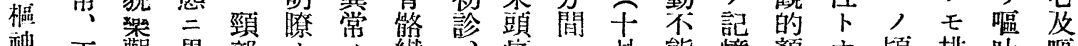

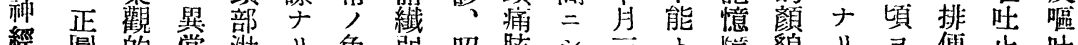

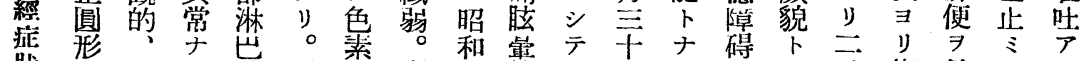

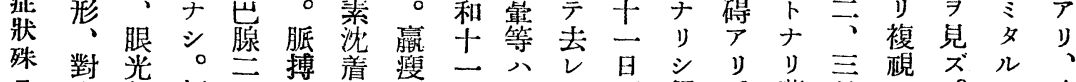

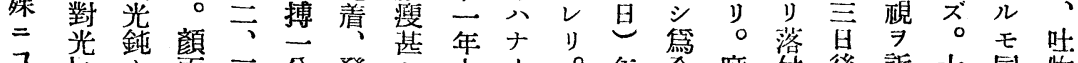

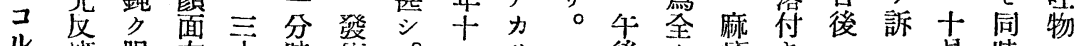

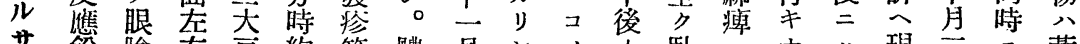

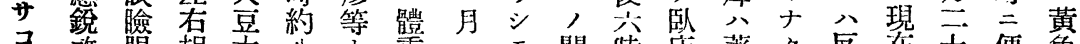

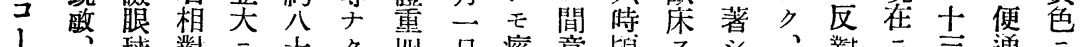
$>$ 球對三十》四日痤意頃

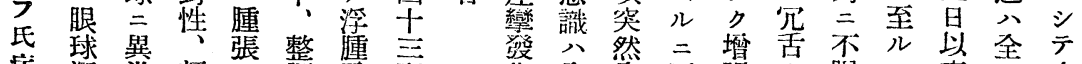

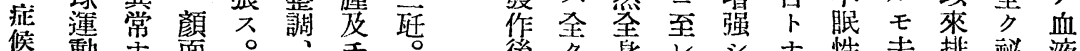

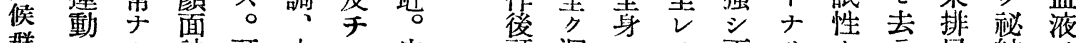

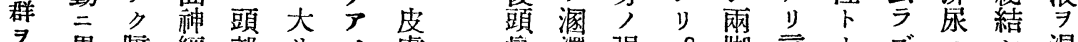

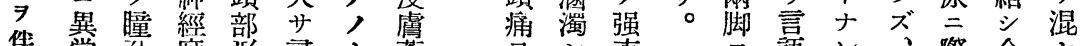

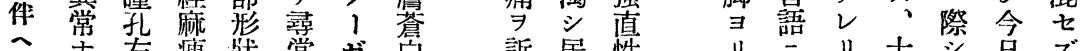

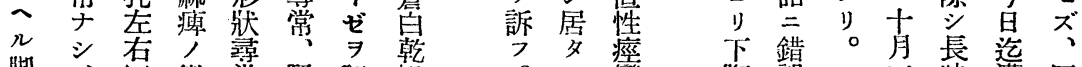

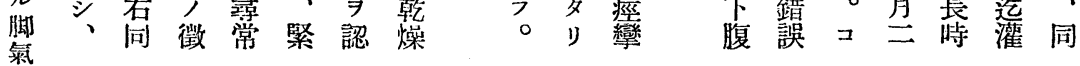

,

例 並及区肢壬常股度高吸進心八於左垂灰眼

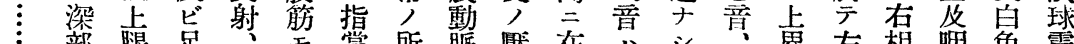

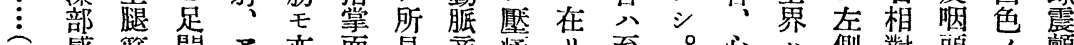

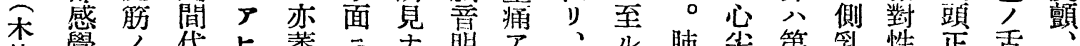

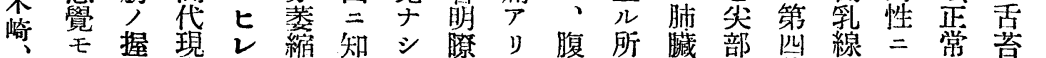

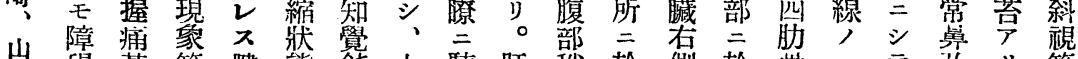

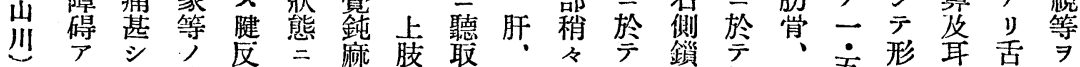

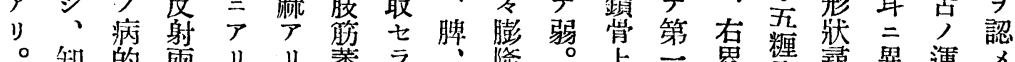
尿知的兩り、萎

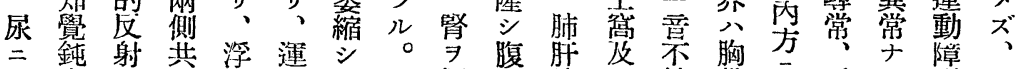
蚠麻于全腫動、下觸壁境 ビ純党云呼 シ 碍口

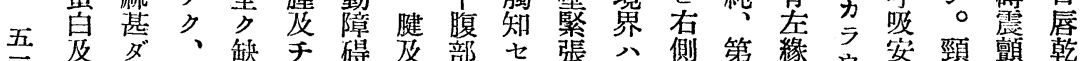

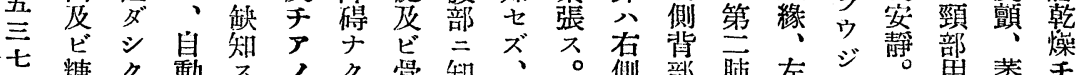

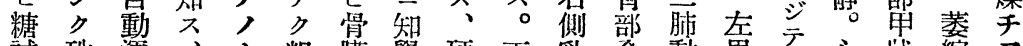

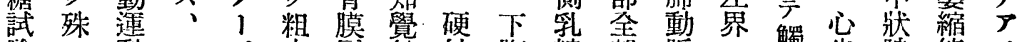

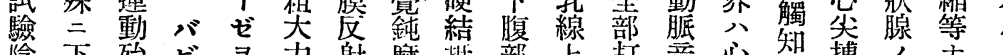
陰下殆ビ 7 力射航些部上打音心知搏, 于1

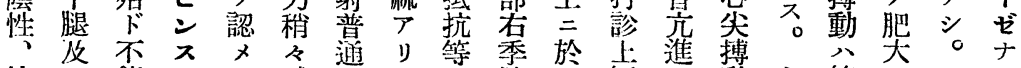

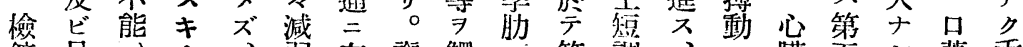

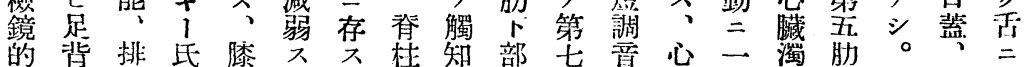

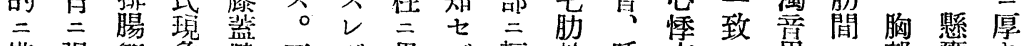

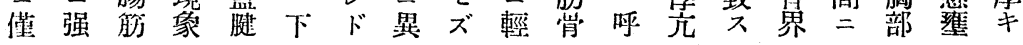


等感 精出右こ齐

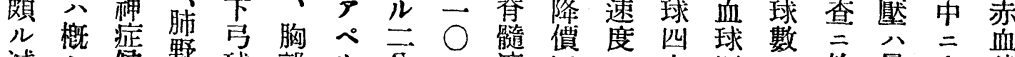

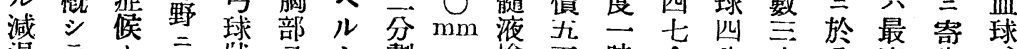

退テ卜二牀 $\ni$ 劃。檢五時

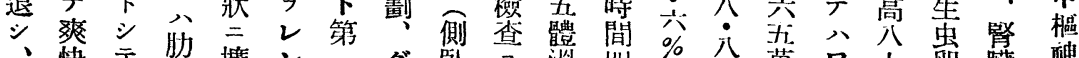

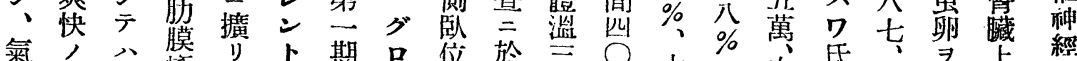

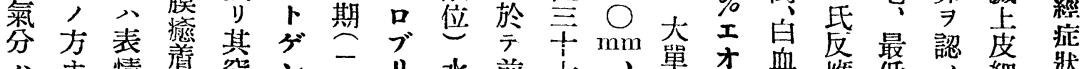

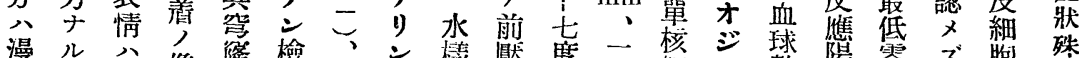

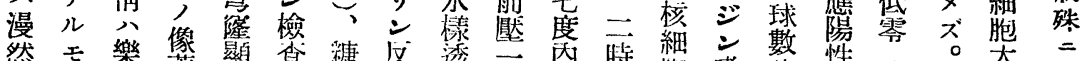

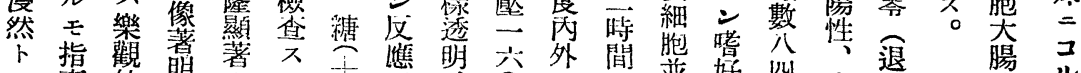

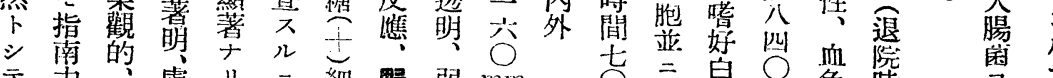
テ椠的虎り

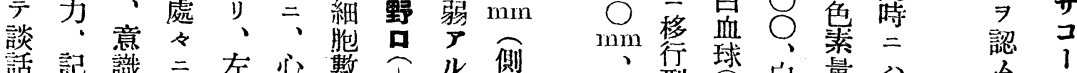

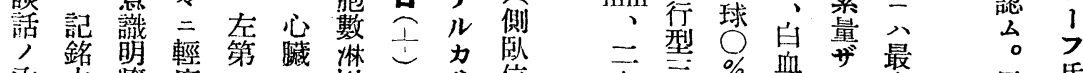

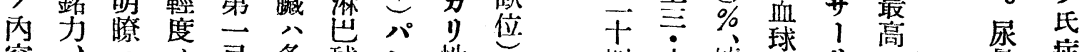

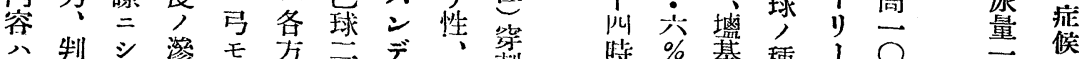

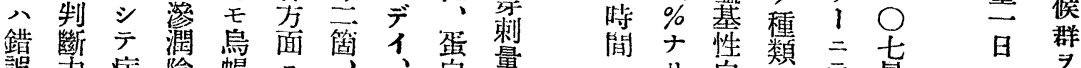
誤甚病覺影帽擴

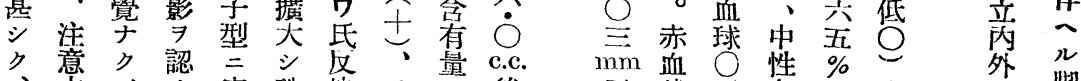

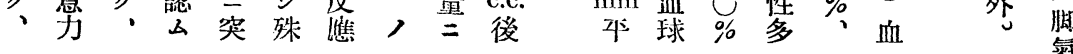

等 7 父閏 正

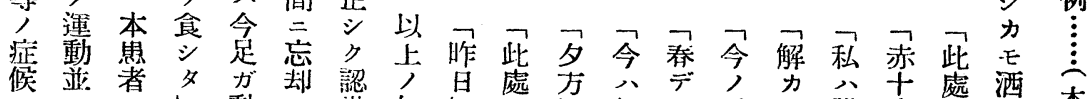

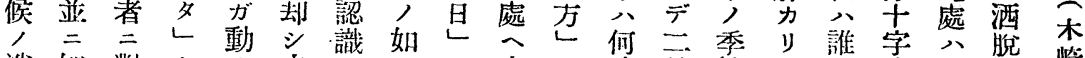

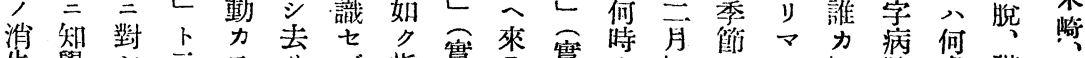

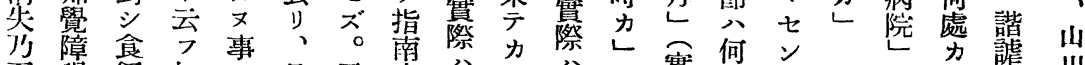

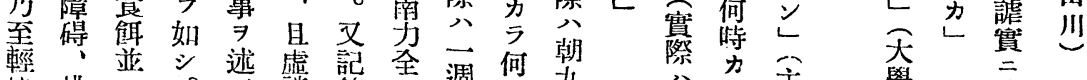

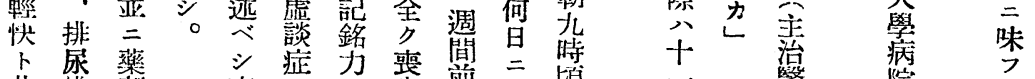

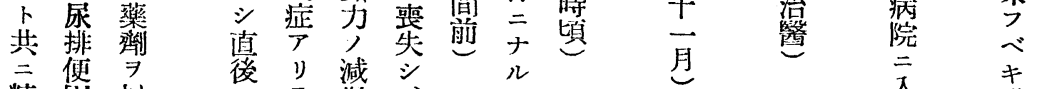

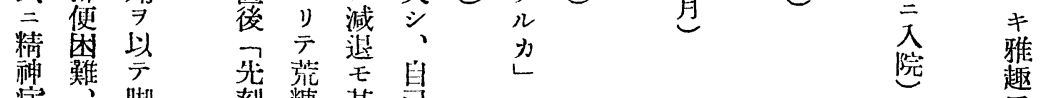

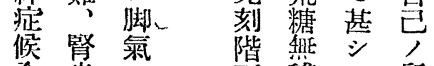

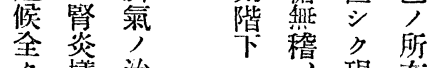
去徽潦歩前在在 、候录 采 後話 環 環 複 七 行錯 タ 境 境覞シ シ テ 認頭卡何 例 事時

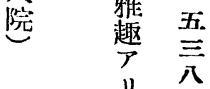
り 試 問 診 ㅈ ル 訬痛肢令人瞬 


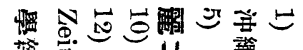

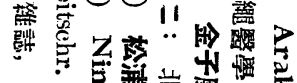

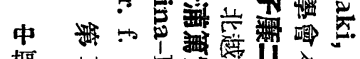

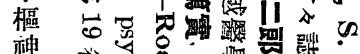

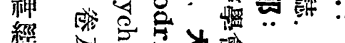

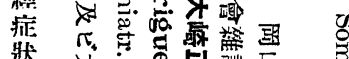

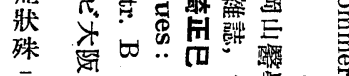

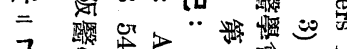

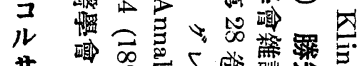

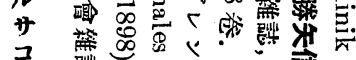

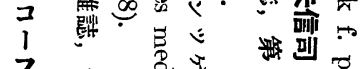

氏

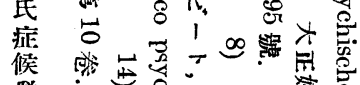

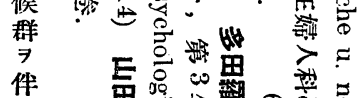

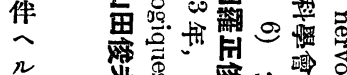

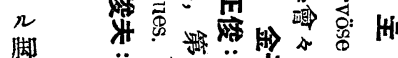

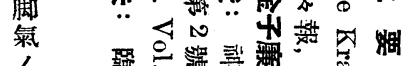

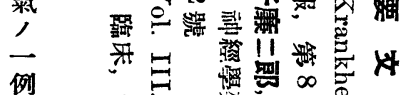

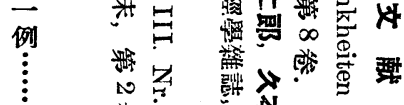

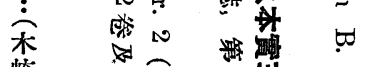

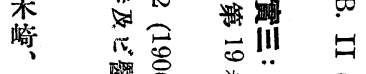

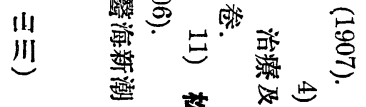

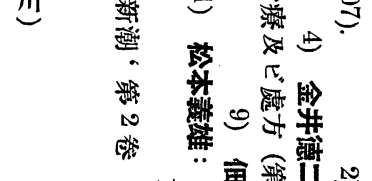

五

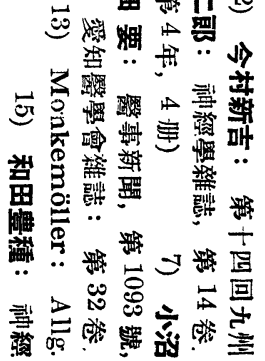

力唒精ガナ重本

、本神レキ篤例

敬擱年例症 ザ處卜公

警箱 症二牀レナナナ脚

意二狀於、霧ドリし氣

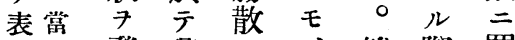

久發興 七、然際罹

。終 シ 味 ル脚 $し$ 或患

始得 $\ni$ 氣 $ト$ 日

御ルル見, モ突ル

愁管八症上然患

馬諸脚 心候上指者

家氣脚最縷南吕

御, 氣激迸力夕

指交經 $\rightarrow$ 烈七茄

導献過以学矢夕

御三中云事方畋

校 $\exists 二 之$ 際 $\exists$ 記賁

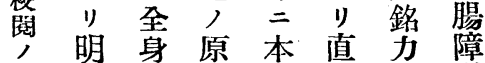

勞力症因症二減碍

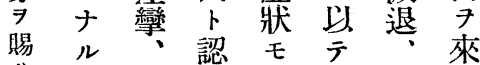

壬複㕕最脚追多

名唒視儿壬氣想七

恩筧事明分錯 几

恩 特 腎 ガ 暸之謨 爲

茫筆焱最二, 甚

教二樣玉現圭盧ダ

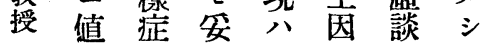

深公候當脚す等 不

謝事膀り氣卜發適

害胱卜累, 現當

併于直思療積 シ

七り腸惟法極更儿

厂 卜障 $九$, 的令食

水思碍 ザ

講惟等

師。是得り下症胜

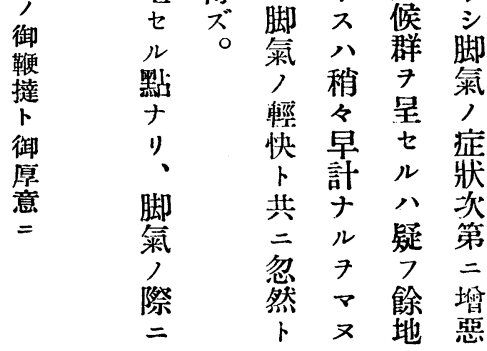

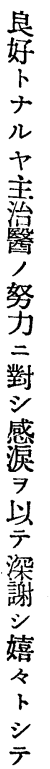

步
行
空
退
院
七
リ
0 
die Venenstämme umgebenden Bindegewebe befinden, nicht aber von den peribronchialen Nervenbündeln. Wir fanden die feinsten Nervenfasern von den Venenstämme an bis in die Gegend der Praekapillaren.

9) Die Ganglien und die Ganglienzellen liegen gerade in der Nähe der grossen Arterien und Venen. Doch sind sie in der Nähe der ersteren Gefässe viel weniger als in der der letzteren.

(Autoreferat)

\section{Ein Fall von Beriberi mit Symptomen von seiten des Zentral- nervensystems, besonders dem Korsakowschen Symptomenkomplex.}

$$
\text { Von }
$$

Dr. K. Kisaki und Dr. U. Yamakawa.

(Aus der 1. Med. Klinik der Kaiserl. Univers. zu Kyoto in Japan.

Direktor: Prof. Dr. K. Tsuji)

Die Verfasser hatten Gelegenheit, einen interessanten Fall von Beriberi zu beobachten.

Bei dem 51-jährigen Patienten, der vor einigen Jahren an Beriberi erkrankte und wegen Magendarmstörungen sehr mangelhaft und einseitig ernährt worden war, kam es mit der Verschlimmerung der Beriberisymptome zu psychischen Störungen, wie Desorientiertheit, Verlust der Merkfähigkeit und Konfabulation.

Die Verfasser hielten solche Erscheinungen für einen durch Beriberi entstandenen Korakowschen Symptomenkomplex und behandelfen den Kranken gegen die Beriberi. Dabei erholte sich der Kranke allmählich, und zugleich traten mit der Besserung der Beriberi die psychischen Störungen in den Hintergrund.

Als interessante Erscheinungen fanden sich bei diesem Fall allgemeine Krämpfe, Diplopie, nephritischer Harnbefund und Blasenmastdarntstörungen.

(Autoreferat) 